\title{
Práticas e concepções de psicólogas/os em serviços públicos de Saúde e Assistência Social na Bahia frente à queixa escolar
}

\begin{abstract}
Resumo: O presente estudo tem como objetivo analisar as concepções e práticas de psicólogas/os que atuam nos serviços públicos de Saúde e Assistência Social que recebem demandas escolares. Como resultado dessa aspiração, foram realizadas e conduzidas entrevistas em grupo nas quais participaram cinco profissionais que trabalham no Centro de Atenção Psicossocial, Centro de Referência em Assistência Social e no Centro de Referência Especializado em Assistência Social da Bahia. A análise indica que as/os profissionais têm buscado compreender a queixa escolar superando a abordagem medicalizante relacionada a essas demandas, ampliando a articulação com a escola, com a família e com a comunidade. O fortalecimento das Políticas Públicas na garantia dos direitos sociais tem sido dificultado pela precarização dos serviços e da condição de trabalho das/os profissionais, bem como a própria construção histórica e ideológica sobre o fracasso escolar.
\end{abstract}

Palavras-chave: Saúde; Assistência Social; Queixa Escolar.

\section{Practices and Conceptions of psychologists in public services of Health and Social Assistance in Bahia to the school complaint}

\begin{abstract}
The present article has the goal to analyze the conceptions and practices of psychology professionals who work in the public services in the Health area and Social Assistance that receives educational demands. As a result of this aspiration group interviews were conducted in which five professionals who have been working in Centers for Psycho-social Attention, Assistance Reference Centresand Specialised Social Assistance Reference Centresin Bahia. The analysis indicates that the professionals have been searching the understanding of the school complaint in a way to overcome the medicalizing approach related to these demands in order to expand the articulation with the schools such as the family and the community. The strengthening of the Public Politics in the sense of social rights' assurance have been hampered by the precariousness of public services and by the working conditions of the professionals as well as the own historical and ideological construction of the school failure.
\end{abstract}

Keywords: Health. Social Assistance. School Complaint.

O presente artigo tem como objetivo identificar e analisar concepções e práticas desenvolvidas por um grupo de psicólogas/os que atuam nos serviços públicos de assistência social e de saúde na Bahia frente às queixas escolares. Essa pesquisa ${ }^{1}$ é desdobramento do estudo mais amplo, realizado por Viégas (2014) cujo resultado indicou a presença de poucas/os psicólogas/os trabalhando na
Liliane Alves da Luz Teles Universidade Federal da Bahia lili_psiquee@hotmail.com

Klessyo Espírito Santo Freire Universidade Federal da Bahia klessyo@gmail.com

Kátia Oliveira

Universidade Federal da Bahia katia08oliveira@hotmail.com
(1) Trata-se de uma pesquisa interinstitucional, com financiamento da Fundação de Amparo a Pesquisa do Estado da Bahia (Edital n011/2013) com objetivo de fazer um levantamento dos psicólogos que atendem demandas escolares em todo o Estado nos serviços públicos citados. 
educação pública do estado. Dessa forma, as demandas escolares que seriam endereçadas a elas/eles, estavam sendo encaminhadas para a Saúde Mental e Assistência Social, destacadamente os serviços de Centro de Atenção Psicossocial (CAPS), Centro de Referência em Assistência Social(CRAS) e Centro de Referência Especializado em Assistência Social (CREAS), já que nestes há a presença de psicólogas/os no quadro funcional. Dessa forma, buscamos aprofundar a compreensão sobre as concepções que respaldam as práticas dessas profissionais, à luz das principais contribuições da psicologia escolar e educacional na perspectiva crítica, bem como da sua compreensão sobre queixa escolar.

A psicologia escolar e educacional na perspectiva crítica surgiu a partir da obra da pesquisadora Maria Helena Souza Patto (1984; 1999). Nela, questionou-se às explicações hegemônicas sobre o fracasso escolar que atribuíam às causas desse fenômeno à criança e a sua família, seja por causa das supostas diferenças individuais biologicamente herdadas ou por uma "carência cultural das classes pobres". Patto (1984) também denunciou o quanto historicamente, a ciência psicológica se constituiu visando promover o ajustamento do indivíduo a sociedade com a finalidade de manter o status quo. A perspectiva crítica questiona as relações de cumplicidade entre ciência e ideologia, reconhecendo o reducionismo individualizante de questões sociais que estão presentes histórica e hegemonicamente na Psicologia. Esse reducionismo captura a leitura do mundo, produz explicações tautológicas, e mascara a necessidade de questionar e transformar a essência da produção dessas desigualdades. Com isso, uma perspectiva crítica em psicologia escolar e educacional desloca o olhar que outrora buscava nas crianças e em suas famílias a razão do não aprender, para uma análise mais complexa, levando em consideração os fatores macroestruturais, históricos, políticos, sociais, econômicos e relacionais que produzem e mantém condições de exclusão e desigualdade.

O encaminhamento das demandas as/aos psicólogas/os e, consequentemente, aos serviços de saúde e assistência, é um efeito dessa lógica, que desconsidera os determinantes sociais na produção da queixa escolar como um fenômeno exterior à escola. Ao atender a queixa escolar desconsiderando os fatores citados, atende-se a um modelo medicalizante, contribuindo para a exclusão de crianças e adolescentes, sobretudo das classes pobres. A medicalização é entendida como um processo em que: 
Medicalização envolve um tipo de racionalidade determinista que desconsidera a complexidade da vida humana, reduzindo-a a questões de cunho individual, seja em seu aspecto orgânico, seja em seu aspecto psíquico, seja em uma leitura restrita e naturalizada dos aspectos sociais. Nessa concepção, características comportamentais são tomadas apenas a partir da perspectiva do indivíduo isolado, que passaria a ser o único responsável por sua inadaptação às normas e padrões sociais dominantes. A medicalização é terreno fértil para os fenômenos da patologização, da psiquiatrização, da psicologização e da criminalização das diferenças e da pobreza. (FÓRUM..., 2015, p. 1)

A tendência em compreender como doença aqueles que vivenciam dificuldades no processo de escolarização, reduzindo o olhar ao indivíduo e adotando explicações organicistas para o fenômeno, não apenas produz ainda mais sofrimento e estigma, como também, contribui para a manutenção das desigualdades sociais, ao não questionar as engrenagens que mantém o funcionamento da política de exclusão que fragiliza os mais vulneráveis. Embora a literatura na área seja densa, questionando o papel da Psicologia no atendimento às demandas escolares no modelo clínico tradicional e medicalizante, sabemos que o avanço da profissão carrega contradições e esta modalidade continua presente de forma hegemônica.

O encaminhamento das queixas escolares aos profissionais da área de saúde (incluindo as/os psicólogas/os) carrega em si a concepção medicalizante na explicação sobre o porquê às crianças "não aprendem/não se comportam". É inegável que os serviços citados avançaram na concepção da "promoção de saúde" e proteção social, através de políticas que incluem a articulação com o território e superam o modelo biomédico e clínico tradicional. Assim, o acolhimento às demandas escolares nesses equipamentos revela uma complexidade que precisa ser compreendida de forma multifatorial, tendo como uma das principais finalidades a proteção dos direitos da sociedade, especialmente daqueles considerados mais vulneráveis. Dessa maneira, buscamos compreender o encaminhamento de crianças aos equipamentos de Saúde (CAPS) e Assistência Social (CRAS e CREAS), pelas especificidades que tais equipamentos possuem, para entender como psicólogos que neles atuam, acolhem e entendem estas demandas, levando em 
conta que a sua inserção da profissão de forma significativa nas políticas públicas ocorreu, sobretudo, na década de 1990.

\section{O papel social do CAPS, CRAS e CREAS}

Para contextualizar, a história do CAPS, ele surgiu a partir da Luta do Movimento dos Trabalhadores de Saúde Mental (MTSM), que surge no ano de 1978, considerado o "início efetivo do movimento social pelos direitos dos pacientes psiquiátricos em nosso país". (BRASIL, 2005, p. 6) Sendo uma política recente, o primeiro CAPS no Brasil foi fundado em 1987, em São Paulo, mas somente em 2002 ele foi efetivamente regulamentado com chamada Lei Antimanicomial através da Portaria $n^{0}$ 336/02, que versa sobre a criação e funcionamento dos serviços substitutivos ao hospital psiquiátrico, definidos como:

[...] serviços de saúde municipais, abertos, comunitários, que oferecem atendimento diário às pessoas com transtornos mentais severos e persistentes, realizando o acompanhamento clínico e a reinserção social destas pessoas através do acesso ao trabalho, lazer, exercício dos direitos civis e fortalecimento dos laços familiares e comunitários. (BRASIL, 2005, p. 9)

O equipamento é subdividido em modalidades que se diferenciam pelo "porte/complexidade e abrangência populacional". (BRASIL, 2002, p. 1) Essa modalidade de atenção em saúde mental é compreendida como serviço estratégico nessa rede por conta da sua função que se delineia em:

[...] prestar atendimento clínico em regime de atenção diária, evitando assim as internações em hospitais psiquiátricos; promover a inserção social das pessoas com transtornos mentais através de ações intersetoriais; regular a porta de entrada da rede de assistência em saúde mental na sua área de atuação e dar suporte à atenção à saúde mental na rede básica. (BRASIL, 2005, p.9)

No que tange o CRAS e o CREAS, são políticas públicas instituídas a partir da reformulação da Política Nacional de Assistência Social - PNAS 2004, cujo foco é a proteção social, garantindo: "segurança de sobrevivência (de rendimento e de autonomia); de acolhida; de convívio ou vivência familiar." (BRASIL, 2004, p. 31). 
Para efetivação da perspectiva de proteção social básica e especial, o CREAS e o CRAS foram implantados fazendo parte do Sistema Único de Assistência Social (SUAS).

O CRAS é um dispositivo público do Estado que considera o número de habitantes por município e é instalado em áreas de vulnerabilidade social. (BRASIL, 2004a) Sua função é prestar serviços como organização e coordenação da rede assistencial local, desenvolver o trabalho com famílias e indivíduos, orientando e promovendo o convívio social, familiar e comunitário naquele espaço. Além disso, é responsável pelo desenvolvimento do Programa de Atenção Integral às Famílias. (BRASIL, 2004)

O CREAS é um dispositivo público do Estado que atua diretamente com famílias e indivíduos que se encontram em situação de violação dos direitos, fazendo uma interface contínua com o Poder Judiciário e o Ministério Público. São linhas de frente dessa construção, terreno de estabelecimento de vínculos sociais e institucionais, como também um local de práticas educativas, prevencionistas e principalmente, empoderadoras.

\section{A INSERÇÃO DA PSICOLOGIA NAS POLÍTICAS PÚBLICAS}

A psicologia é uma profissão recente no Brasil, a sua regulamentação ocorreu em 1962 com promulgação da Lei no 4.119. A partir da década de 1970, ela passou por um processo de expansão grande, decorrente da popularização dos saberes psicológicos e da proliferação de cursos universitários. A sociedade brasileira passou a demandar por serviços psicológicos, no entanto, o modelo hegemônico das demandas sociais estava pautada no atendimento clínico. A psicoterapia advinda de um modelo clínico tradicional, herança da medicina, passou era predominante nas atividades profissionais da psicóloga, sobretudo no contexto político da ditadura militar por ser um dos poucos espaços de expressão que não era considerado ameaçador pelos militares. Por ser um espaço que privilegiava o íntimo e privado, a psicoterapia era vista como um terreno fértil para silenciar e ocultar as questões sociais do país. (PEREIRA; PEREIRA NETO, 2003)

A psicoterapia também refletia o ideal do trabalhador autônomo valorizado socialmente no contexto da época. Com isso, o modelo clínico tradicional e a psicoterapia passaram ter uma grande ênfase na formação em psicologia, em detrimento de outras áreas. Porem, o fim do regime militar na década de 1980, o fim da União Soviética e a ascensão dos governos liberais trouxeram 
mudanças sociais significativas que alteraram o panorama da profissão. (PEREIRA; PEREIRA NETO, 2003)

Esse contexto resultou em um achatamento das classes médias e alta que, aliado a expansão do número de cursos de psicologia, causou a saturação da atividade de psicoterapia de consultório. Então, a psicóloga começou a se inserir no mercado de trabalho como profissional trabalhador assalariado, sobretudo no serviço público. A expansão de vagas no serviço público na década de 1990 teve como fator catalisador o surgimento do Serviço Único de Saúde (SUS) e a reforma psiquiátrica. (CARVALHO; YAMAMOTO, 2002)

A inserção da psicologia nas Políticas Públicas foi resultado das lutas de movimentos sociais no fim do regime militar e da crise do sistema- assistencial- privado. Yamamoto (2007) destaca a importância do envolvimento da Psicologia na década de 1980 no movimento de saúde, com a participação expressiva na luta antimanicomial, que definiram condições para a inserção da categoria no campo da garantia de direitos. O autor discute ainda, o sentido das Políticas Públicas como resultante das estratégias do Estado frente às questões sociais, traduzidas como "[...] manifestação no cotidiano da vida social da contradição capital - trabalho". (YAMAMOTO, 2007, p. 31) Assim, a partir da inserção nas políticas públicas, a psicologia necessitou pensar em novos modelos de atuação, que diferiam do modelo clínico tradicional. Uma atuação que considera as múltiplas determinações econômicas, sociais e políticas que subjazem o fenômeno psicológico. (CARVALHO; YAMAMOTO, 2002; PEREIRA; PEREIRA NETO, 2003).

Nessa direção, a profissão "[...] entendida como uma prática institucionalizada, socialmente legitimada e legalmente sancionada" (YAMAMOTO, 2007) atua em equipes inter e multidisciplinares e tem como foco o indivíduo e o coletivo, considerando as diversas desigualdades de gênero, raça, classe, etc., presentes no Brasil. A partir da inserção na saúde pública e dos novos modelos de atuação, a psicologia começou a reivindicar sua participação em outras grandes políticas públicas, a exemplo da educação e assistência social. (CARVALHO E YAMAMOTO, 2002; PEREIRA; PEREIRA NETO, 2003)

Isso culminou na consolidação da profissão nas políticas públicas, sobretudo nos anos 2000 com a regulamentação dos CAPS e a criação dos CRAS e CREAS como estratégias de garantia de 
direitos sociais, nos quais a/o profissional psicóloga/o é convocado a compor as equipes mínimas, dado o reconhecimento que temos avançado na ampliação dos limites da dimensão política da atuação profissional. Nessas Políticas, que têm como fundamento a transformação na condição de vida da população no sentido de superar a desigualdade social, a/o psicóloga/o é convocada/o a considerar as correlações de forças historicamente instituídas, para o avanço das políticas sociais no campo acadêmico, teórico e técnico contra-hegemônico

Em nossa pesquisa, discutimos como os equipamentos que lidam com a infância e adolescência têm recebido demandas escolares, principalmente na Bahia. Esse fato acontece devido presença reduzida de psicólogas/os trabalhando nas escolas públicas ou secretárias de educação no estado, resultando que a demanda endereçada a elas/es, vêm sendo direcionada para os CAPS, CRAS e CREAS, dado este encontrado em pesquisa realizada por Viégas(2014). Assim, profissionais de Psicologia que atuam nesses espaços têm sido convocadas/os a lidar com essas questões no seu dia a dia. Portanto, o foco deste artigo é compreender como essas demandas escolares têm sido entendidas e acolhidas por essas/es profissionais, levando em consideração as discussões e as críticas realizadas pela psicologia escolar e educacional em uma perspectiva crítica relativas a forma de atender essas demandas. Para a análise dos dados foi feita uma análise qualitativa utilizando a estratégia de retardamento da categorização, presente em Michell Thiollent (1980).

\section{Método}

Realizamos uma entrevista de grupo no qual participaram cinco profissionais que atuam nestes equipamentos sediados na Bahia, sendo um no CAPS infantil, um no CAPS, e trêsno CRAS. Vale ressaltar que a pesquisa foi submetida e obteve aprovação no Comitê de Ética em Pesquisa, conforme parecer no 352. 99607/08/2013 relativo à Resolução no 510/16, do Conselho Nacional de Saúde, que regula a avaliação da ética em pesquisa nas Ciências Humanas e Sociais. A pesquisa foi ampla e envolveu diversas etapas e métodos (mapeamento das/os profissionais que atuam nestes serviços; aplicação de questionário; entrevista individual e por fim, a entrevista grupal). O presente artigo é resultado da

revista entreideias, Salvador, v. 7, n. 1, p. 75-96, jan./jun. $2018 \quad 81$ 
última etapa, seu planejamento foi pensado ao observar a necessidade de analisar questões que não foram suficientemente aprofundadas nas etapas anteriores da pesquisa. Foi desenvolvida a partir de cinco grandes eixos: a formação; a vida profissional; as condições de trabalho; o acolhimento de demandas escolares (de que forma a compreendiam e atendiam); os desafios e estratégias desenvolvidas na prática profissional.

A entrevista grupal foi aberta, permitindo a interlocução entre as/os participantes. Seu método proporcionou a todas/os expor seus pontos de vista, suas experiências, mas também a formulação de questões no próprio grupo, intervindo na dinâmica grupal, tecendo comentários sobre as discussões e experiências compartilhadas. Os pesquisadores atuaram como objetivo moderar a discussão para focalizar e aprofundar as questões citadas, registrando as falas para que, junto à transcrição, subsidiasse a análise dos dados. Os resultados foram organizados a partir do discurso das/os participantes, levando em consideração as concepções sobre as demandas produzidas e as nuances de sua atuação.

\section{Resultados}

Participaram do grupo focal cinco profissionais com idades entre 29 e 35 anos, três homens e duas mulheres, sendo dois concursados e os demais exerciam prestação de serviço por meio de contrato. Em relação ao tempo de atuação no equipamento, todas/ os tinham vínculo há menos de quatro anos. O perfil delas/es converge com as análises feitas pela profissão no país: mulheres, adultas/jovens e com o vínculo de trabalho por contrato. (BASTOS; GONDIM, 2010)

Embora dois profissionais tivessem relatado uma formação densa no campo das políticas públicas, os demais se queixaram dessa deficiência, no entanto, buscaram uma formação complementar em pós-graduação e residência multiprofissional em saúde para seu exercício.

Observamos no discurso das/os participantes um esforço para repensar as concepções vigentes e problematizar o jogo de forças presente numa relação que historicamente produz estigma, preconceito, exclusão e subordinação. Ao entrar em contato com a demanda, eles são provocados a pensar a realidade escolar a partir da articulação com a escola, e, desse modo, revelam a 
visão que sustenta a concepção da queixa, do papel do aluno, da família e da escola.

A queixa escolar é uma denúncia, conforme a construção da literatura no campo educacional, sendo entendida como um pedido de ajuda da escola para as dificuldades vivenciadas, embora ainda seja explicada como algo externo à vida escolar (SOUZA, 2010). Desse modo, um conceito central na análise dos dados presente nas falas das/os participantes é a necessidade de problematizar e desconstruir a queixa, sendo um caminho potente que está presente tanto na concepção desta, quanto na prática profissional, conforme se revelam nestas falas:

Então, problematizar, contextualizar, não ter medo do fracasso, não assumir a postura de 'são salvador'. Eles tentam colocar isso na gente, né? E eles acham mesmo que a gente tem leitura de bola de cristal, adivinhação de pensamento, está no imaginário, está no inconsciente coletivo. (S1)

Nessa devolutiva com a escola é importante também que a escola problematize a sua responsabilização, de adequação, de que tem exigências que algumas crianças não têm condições de responder, alguns adolescentes não têm condições de responder. (S4)

E essa desconstrução, acho que a gente está num momento de revelar né? Levar esse novo modo de se olhar para as questões de aprendizado, para as questões de convivência e para a questão do adoecimento mesmo, né? (S3)

Acho que nosso papel é muito de desconstrução mesmo, né? (S5)

As ideias "problematizar, desconstruir, ampliar o olhar" presente nas falas têm sido um dos caminhos adotados na análise crítica sobre o fenômeno, entendendo-a como um fenômeno produzido por uma rede de relações que inclui a família, a escola e a própria criança, mas que é síntese de múltiplas determinações. É necessário acolher a queixa a partir de sua singularidade, valorizando as experiências capazes de produzir um deslocamento do lugar de estigma e sofrimento que marca a trajetória escolar daqueles que chegam ao serviço. Essa atuação contribui para sua elaboração, buscando um trabalho de forma que possa romper com situações cristalizadas para a superação do modelo medicalizante, conforme aponta a seguinte fala:

revista entreideias, Salvador, v. 7, n. 1, p. 75-96, jan./jun. $2018 \quad 83$ 
Existe uma fragilidade de adequação aquele sistema, aquela metodologia de ensino, aquele conteúdo programático, e aquelas atividades estabelecidas ali. Mas, o que há de possibilidades nesse contexto aqui? Que é o que você está trazendo agora. E isso abre portas para que o processo de aprendizado e de construção do conhecimento seja mais criativo mesmo, não é? (S2)

Desse modo, a literatura na perspectiva crítica aponta que é necessário levar em consideração a natureza da queixa escolar, ao invés de deixá-la de lado. Essa concepção difere da abordagem tradicional na Psicologia, que busca explicações intrapsíquicas ou nas relações familiares às causas do fracasso escolar. Para isso, é necessário romper com a ideia de que o problema é da criança, e sim envolver a instituição para uma postura ativa na busca das estratégias em parceria com a família e a própria criança. O modo como as/os profissionais compreendem o processo do acolhimento da demanda é fundamental para a realização de um trabalho em conjunto. Porém, foi possível observar ainda uma culpabilização da família como produtora do fracasso escolar, como pode ser vista na fala abaixo:

Eu só queria pontuar assim, que quando eu trouxe sempre a família, não é no sentido de culpabilização. Ai eu acho que ai, nem de culpabilização nem de vitimização. Mas por entender que o sofrimento ele é produzido no sistema. E pensar que não tem como você cuidar de uma criança com histórico de isolamento, histórico de agressividade sem entender como é que está o contexto dessa família e pensar estratégias de cuidado mais ampliados. É o que há de mais funcional na criança né? Uma expectativa funcional, a criança que está bem é a que aprende, se ela não está bem ela não vai aprender. E ela não consegue aprender às vezes porque tem um sofrimento que é produzido dentro desse contexto de família. E a criança é que têm menos defesas, menos estratégias. (S1)

É importante destacar que os serviços de saúde e assistência social lidam cotidianamente com um público em situação de vulnerabilidade social, pois este é o foco prioritário dessas políticas. Desse modo, a concepção de que os problemas sociais podem produzir conflitos nas relações familiares não podem ser analisados desconsiderando a desigualdade, que ressoa antes de tudo, num reflexo de um estado onde direitos e cidadania ainda 
se constituem como ideais. Para incorporar tal análise nesta discussão é importante pensar que nesta mesma sociedade desigual, que viola o direito a uma educação de qualidade, produz também todo tipo de violência que repercute na construção das subjetividades, nas relações pessoais, especialmente familiares. Desse modo, mesmo quando pensamos no sofrimento produzido nas relações familiares, não podemos tomá-lo como causa, mas como consequência de uma rede de tensionamento e exclusão que afeta uma grande massa. Como as/os profissionais citaram ao relatar sobre a dificuldade que as famílias encontram ao lidar com uma postura autoritária e preconceituosa que muitas vezes a escola adota:

\begin{abstract}
Acho que é mais sério quando a família relata: 'Eu vim porque a escola disse que se meu filho não passasse por um psicólogo ele não poderia ser matriculado'. É meio que uma questão condicionante, né? O acompanhamento. (S1)

Então a queixa existe mas a demanda nem sempre vai ser genuina, nem sempre vai ser valorizada. Muitas vezes eles vão só por ir, e chegam lá dizendo: 'Eu vim aqui porque a professora mandou e se não vier não entro mais na escola'. Em que astral essa familia chega, com que expectativa ela chega ao serviço? Da mesma forma uma queixa vinda do conselho tutelar, que se forma uma demanda muito assim, frágil, que eles vêm também obrigados a vir: 'O conselho mandou eu vim aqui trazer meu filho'. (S3)
\end{abstract}

A concepção que acolhe e busca novas formas de compreender a queixa exige repensar o modo como a escola se organiza diante dos desafios diários na construção de novos olhares sobre a aprendizagem e o comportamento das crianças. As/os entrevistadas/os reconhecem que a Psicologia pode contribuir ou não para repensar as práticas de encaminhamento, o olhar "queixoso". Mas é necessário repensar o próprio papel da profissão como mola propulsora dessas demandas. É importante estar atenta/o ao lugar que a psicologia ocupa, como podemos analisar a partir das falas elucidadas:

E como é que a gente oferece isso aos professores né? Em parceria né? De chegar e dizer que a gente não está lá para responsabilizálo ainda mais, para dar mais trabalho para eles, pelo contrário, a gente está lá para estabelecer um debate, um

revista entreideias, Salvador, v. 7, n. 1, p. 75-96, jan./jun. 201885 
diálogo e entender de que forma está sendo tudo construído. A gente também tem muitas dúvidas, eles têm muitas dúvidas, mas quando a gente se junta, são criados caminhos de possibilidades muito contentes. (S4)

A gente teve uma experiência, a gente percebe uma diferença gritante, entre a demanda, ser solicitado pela escola e de a gente ir lá oferecer (risos). A gente sente essa diferença né? Assim, a gente vai: ah olha viemos falar sobre saúde mental. Percebemos que tem alguns casos aqui, queremos trocar umas ideias com vocês.

Quando a gente vai levar, parece que é muito mais uma coisa assim: 'ah, é mais trabalho que vem pela frente'.(S2)

Nessas falas é possível perceber que há espaço possível para a Psicologia, desde que atenta às especificidades que já foram apontadas na literatura, e que Souza (2009) resume em três importantes eixos:

a) a importância de pesquisarmos os fenômenos educacionais a partir dos processos que acontecem no interior da escola; b) a necessidade de encontrar modelos teórico-metológicos que superassem a noção unilateral de adaptação da criança ao sistema escolar; c) o destaque para a necessidade de autonomia do trabalho do psicólogo em relação ao corpo dirigente da instituição escolar. (SOUZA, 2009, p. 180)

Esta perspectiva aponta para a importância de outro lugar para o trabalho da Psicologia, que possa considerar a relação entre professor e aluno como construção diária, mobilizando sentimentos e criando novas possibilidades para o lugar e a representação que ambos ocupam. Este trabalho também deve considerar a escola historicamente construída, cuja complexidade transcende a relação professor-aluno.

Embora haja um olhar ampliado sobre a concepção da queixa escolar e sobre o papel da Psicologia para romper à lógica medicalizante, a prática profissional é atravessada por diversos tensionamentos que se colocam como desafios na tentativa de construir uma atuação ético-tecnicamente fundamentada na análise crítica das demandas, por meio do exame de abordagens que, diante da queixa escolar, possibilite uma atuação que leve em consideração as múltiplas determinações que a compõem. Identificamos que as/os profissionais têm desenvolvido formas de atuar no atendimento à queixa escolar a partir das práticas de matriciamento, 
visitas à escola, orientação à família e à escola, problematização da queixa e articulação com o território. O matriciamento é uma estratégia prevista na Saúde Mental originado nos anos de 1990, que tem como foco a articulação entre serviços, necessária para a formação de uma rede colaborativa, cujo suporte é realizado por equipe multiprofissional. Tem como foco o cuidado ampliado e a integração entre a saúde básica e saúde mental (BRASIL, 2011). Conforme citado, as/os entrevistadas/os buscam estabelecer uma atuação que inclui a proposta de matriciamento, como pode ser visto abaixo:

O matriciamento é o espaço para se trabalhar essas questões. No meu caso não com as escolas, não cheguei às escolas ou ter um programa especifico ou projeto específico ou momento especifico com as instituições. Mas com a família, com os profissionais de saúde sim, buscando ampliar mesmo esse othar. O matriciamento em si já vem para produzir isso, para isso. Reconhecer esse processo como um produtor de qualidade de vida e saúde e empoderador das famílias, dos profissionais para lidar com essas situações, situações problema digamos assim, rotuladas como situações problema. Mas com as escolas não tive essa experiência. (S1)

A gente, na verdade, na época que eu estava na residência, lá a gente tinha a estratégia de matriciamento. Na verdade assim, como uma escola, era meio que um projeto piloto, e ai tinha encontros periódicos para discutir os casos que a escola identificava uma dificuldade de manejo. E a gente chegou a fazer um fórum com as escolas, mas a gente fez um recorte, na época eu não lembro se as escolas eram por distrito, porque assim, a gente atende né? Salvador inteira. Então é isso é uma dificuldade assim, pensar inclusive um processo de matriciamento. (S3)

Há uma preocupação de construir o matriciamento, estabelecendo uma relação de parceria com as/os educadoras/es, de forma a não rotular e estigmatizar as/os alunas/os, que é dificultado quando o equipamento tem um território muito grande e apenas uma equipe responsável. A articulação com o território é uma estratégia fundamental para o desenvolvimento do matriciamento.

Quando não é possível fazer o matriciamento, as/os profissionais tentam fazer visitas à escola como uma forma de acolher a demanda. Esta se diferencia do matriciamento, pois consiste em realizar um diálogo mais pontual, ou seja, um caso do um/uma aluno/a atendido no equipamento. Tal estratégia não estabelece 
um vínculo maior com a escola, tanto para o acompanhamento de casos, como para discutir outras temáticas presentes da vida diária escolar, como pode ser vista abaixo:

Tem casos em que a gente acompanha e a escola demanda. A escola está com dificuldade de criar condições para que essa criança $e$ adolescente consiga se desenvolver no ambiente escolar. Então a gente vai à escola e geralmente faz a observação, faz uma conversa com a professora, com a direção, tentando criar estratégias para permanência da criança na escola e de adequação da escola também as necessidades da criança. (S2)

Nessas visitas, observamos a importância dada pelas/os profissionais em "empoderar" as/os educadores para buscar soluções para as dificuldades vivenciadas na escola. Isso significa um esforço em não ocupar um lugar de saber que a Psicologia tem historicamente exercido na relação com as/os professoras/es. Para isso, as/os psicólogas/os ressaltaram que a queixa é multifatorial, está diretamente ligada à escola e as políticas educacionais, envolve questões culturais que discriminam e marginalizam as crianças, produz exclusão na e da escola, como pode ser visto na seguinte situação relatada abaixo:

E eu lembro quando eu conversei pessoalmente, individualmente com a criança, ele falou sobre o estigma dos colegas, porque diziam que ele era mulherzinha. E ele sentia esse incomodo na escola. E essa mãe ela falava até emocionada: 'Poxa, eu luto tanto pelo filho porque eu quero que ele se dê bem nos estudos, ele tenha as oportunidades que eu não tive. A gente estuda em casa e em casa ele aprende, mas não consegue ler na escola. A professora me disse que meu filho não sabe ler. Ele tem livros em casa, ele lê, eu sento com ele e digo: Fitho, vamos ler esse texto? Ele lê todinho, com pontuação, perfeitamente, e porque na escola ele não consegue?'. Não seio que fazer, as professoras se queixam. E aí eu tive esse diálogo com o menino e aí ele me falou sobre o preconceito que ele sofria na escola, uma criança, enfim, com um terrivel mal-estar. E eu precisei esclarecer isso para a mãe, levar isso para ela, que existia um sofrimento do menino na escola, que o fato dele não está indo bem não era por nenhuma deficiência Ela saiu tranquila pelo fato de saber que não existia uma deficiência intelectual, uma deficiência cognitiva que iria comprometer o aprendizado do filho, não era um 'retardado', enfim, e todas essas palavras que ela usou mesmo, 'será que meu filho está ficando retardado? Está ficando doente?' (S1) 
Observa-se a tentativa de um olhar de cunho mais institucional e voltado para os preconceitos e estigmas que estão presentes nas relações, e que produzem sofrimento para a criança e sua família. Estar sensível e atenta/o às questões de discriminação de gênero, racial, de classe, etc. é uma urgência que a Psicologia tem relegado historicamente ao analisar as relações escolares.

Os resultados apontaram ainda que dentre as estratégias de atuação, a orientação as famílias e professoras/es tem sido um dos recursos mais utilizados, quando existe uma dificuldade em estabelecer um acompanhamento mais sistemático. Isso se deve ao volume de demandas ou ao perfil do equipamento, que, em tese, não tem como foco o trabalho com as queixas escolares. De acordo com as/os entrevistadas/os essa estratégia pode ser bem utilizada para repensar as exigências sobre as crianças e adolescentes encaminhados, como aparece nesta fala ilustrativa:

\begin{abstract}
Eu ainda vejo a informação como uma forma muito potente de ajudar assim, famílias de chegar assim e você vê que mudou, ampliou o olhar, já saiu de alguma forma ali inquieta com aquilo Provavelmente ela vai se sentir mais empoderada de questionar o próprio médico se a dosagem se realmente é necessária. Assim como na escola, a gente fazer isso com o professor, junto levar essa informação, ele vai se sentir mais encorajado para lidar com aquela demanda que surge ali, vai pensar duas vezes se pode encaminhar, porque tem a perspectiva da rede é muito...pelo menos na minha vivência é muito difícil, é muito precária. (S3)
\end{abstract}

Ainda, em menor escala, buscam atuar em articulação com a comunidade, as/os participantes ressaltam a necessidade de considerar o território, sua cultura e seu contexto, estabelecendo parcerias, não só com a rede de serviços públicos, como pode observado:

Território, a cultura, o contexto, que já vem de uma perspectiva de um olhar, de um trabalho ampliado. Que saia da instituição, que possa também se articular com a comunidade, não só dos serviços públicos, mas também os comunitários. (S4)

Assim, pode-se ver que as experiências relatadas buscam problematizar as queixas, compreendendo-as como multifatoriais, sendo necessário envolver uma rede complexa que não se restringe aos atores diretamente envolvidos. No entanto, há muitos desafios 
para a construção de caminhos potentes, e estes são citados como entraves para o avanço de práticas mais consistentes. Envolve a insatisfação com a formação, vista como deficitária tanto tecnicamente, quanto do ponto de vista teórico-científico, fundamentais para qualificar o exercício profissional, como citado:

Assim só para gente pensar como se pode dar essa nossa formação desde cedo e como a gente pode depois continuar perpetuando essa prática equivocada, de buscar sempre uma solução, uma resposta e essa busca pode ser muito violenta, reprodutora de muita violência (S1)

Nesta direção, tem se defendido a necessidade de uma formação crítica e socialmente comprometida com a superação das injustiças sociais. Para tal, a atuação nas políticas públicas que tem como foco a garantia dos direitos constitucionais, exige um compromisso ainda maior das/os profissionais na defesa dessa política, na qualidade e no acesso da população aos serviços, como formas de preconizar a integralidade e equidade da mesma.

As condições de trabalho foram citadas como um dos grandes limitadores no alcance das políticas públicas, comprometendo tanto o exercício profissional, quanto o combate a desigualdade. As relações de trabalho precarizadas, vulnerabilizam o profissional, seja pelo vínculo, seja por formas mais sutis de coação e controle que são implementadas institucionalmente. Sabe-se que na lógica neoliberal os trabalhadores sofrem com seus direitos rebaixados, há uma legitimidade do descarte do trabalhador, intensificação das jornadas de trabalho e baixa remuneração, conforme traz o relato:

Além da precarização do serviço, do salário defasado, do vínculo totalmente precário de trabalho né? Que já tirava um pouco do estimulo né? Porque a gente vai trabalhar na perspectiva de um outro lugar, de galgar uma outra coisa, porém tentando fazer bem aquilo que a gente está ali se propondo a fazer né? E os entraves são imensos, imensos assim. Então eu acho que a gente precisa ainda lutar muito pra qualificar, para que os serviços tenham condição de desenvolver o trabalho com a qualidade prevista com base no SUAS, no seu objetivo. Se é um serviço de base territorial? Se o vínculo é precarizado, como é que você vai colocar uma profissional que você sabe que vai retirar daqui a um ano? Daqui a seis meses? (S2) 
A fragilização do vínculo, como foi citada, não compromete somente a vida desse trabalhador, mas a qualidade do serviço ofertado, trazendo graves consequências ao submeter os profissionais às condições impostas pela necessidade do capital e dos seus gestores, pauperizando-os por interesses políticos e econômicos. Desse modo, não é possível pensar numa atuação socialmente comprometida, quando as relações de poder alienam o trabalhador, impõem formas de amordaçamento, sendo incompatível com o próprio sentido da política que é a garantia dos direitos sociais.

Uma das dificuldades que as/os psicólogas/os relataram enfrentar foi à falta ou fragilização da rede. Faltam serviços e profissionais em seu município para onde encaminhar crianças e adolescentes em casos específicos, resultando no atendimento de casos que não seriam necessariamente para o equipamento onde trabalham. Outra dificuldade enfrentada diz respeito à implementação do próprio serviço e da política, pela inexistência de organização da equipe, precarização do equipamento e falta de condições materiais.

O desafio da construção de práticas que superem a lógica medicalizante esbarra em ganhos secundários que a existência de um diagnóstico traz para a vida de uma população empobrecida. Muitas vezes veem como possibilidade de uma melhoria de renda a presença de um laudo que possibilita o acesso ao recurso disponibilizado pelo Benefício da Prestação Continuada da Lei Orgânica da Assistência Social (BPC/LOAS). O BPC é concedido a pessoas idosas acima de 65 anos ou ao cidadão com deficiência física, mental, intelectual ou sensorial de longo prazo, que o impossibilite de participar de forma plena e efetiva na sociedade, em igualdade de condições com as demais pessoas. Para requerer o benefício, é necessário ter renda per capita de até 1/4 do salário mínimo. Desse modo, acaba-se promovendo uma inclusão perversa, pois como lidar com a desconstrução do diagnóstico uma vez que ele é a garantia do acesso à manutenção de necessidades básicas? Sobre esse dilema, os profissionais entrevistados relatam:

E aí assim, se eu sou doido, se meu filho tem um problema, então ele vai receber um benefício então ele tem que continuar tendo um problema; consciente ou inconscientemente existe uma autorização para que aquele problema permaneça se mantenha, se agrave porque se ele melhorar perde a fonte de renda. É um ganho secundário, assim, perverso. (S1)

revista entreideias, Salvador, v. 7, n. 1, p. 75-96, jan./jun. 201891 
Do mesmo modo, o efeito perverso ressoa na organização escolar, já que a política educacional prevê a redução de alunos em sala de aula nos casos em que há pessoas com necessidades educacionais específicas. A justificativa seria a possibilidade de o professor flexibilizar as atividades e exercer um acompanhamento mais sistemático que demandaria um esforço maior em classes ditas "de inclusão". Assim como, a presença de uma auxiliar na sala de aula pode contribuir para diminuir a sobrecarga dos professores, que precarizados e desvalorizados, vivenciam as burocracias e a massificação do ensino, levando-o também ao sofrimento, como cita uma das profissionais:

\footnotetext{
É porque assim, existe a reclamação: o menino não se comporta, o menino não aprende, tem alguma coisa, tem que ter no laudo, por que assim nós descobrimos também que, numa dessas seções de matriciamento a gente descobriu, porque a gente não sabia que a escola pede um laudo, que um laudo justifica a presença de um auxiliar dentro da sala e que pode contribuir no processo de aprendizagem se ele tiver necessidades especiais, se ele tiver um laudo e ai pá, bota um carimbo, bota um rótulo na criança. (S1)
}

Essas necessidades específicas prescindem do relatório médico atestando o diagnóstico, e desse modo, o enfrentamento do processo de medicalização requer uma sensibilidade para olhar os impactos que o diagnóstico produz, mas ao mesmo tempo, atuar na garantia da melhoria das condições dessa população afetada pela lógica medicalizante e pela pobreza.

O sentimento de solidão, compartilhado pelos profissionais, de "nadar contracorrente", em políticas públicas que tem como foco privilegiado pessoas em situação de grande mazela social, em tempos de desmonte dos dispositivos de garantia de direitos, pode encontrar potência e força nas articulações coletivas. A possibilidade de trocas, de construção criativa para o enfrentamento do tecnicismo nos encontros entre os profissionais, demonstrou ser um caminho promissor para compartilhar saberes, experiências, sentimentos e ações. Na pesquisa, o grupo relatou a possibilidade de refletir sobre sua prática, ressignificando às experiências vivenciadas, possibilitando perceber os potenciais de criação e transformação que carregam no seu fazer. 


\section{Conclusões}

Diante do que foi exposto, embora as políticas de saúde mental e de assistência social tenham avançado na garantia de direitos, nota-se a falta de investimento, infraestrutura, e problemas com a organização das equipes que têm impactado de forma proeminente a atuação dessas/es profissionais. A diversidade e complexidade das demandas que chegam aos equipamentos, que têm como foco um público em situação de grande vulnerabilidade, dificulta uma atenção especializada sobre a queixa escolar, embora ao lidar com a infância e adolescência, a escolarização constitui-se como um aspecto fundamental a ser trabalhado. Apesar desses serviços não serem voltados para o atendimento das queixas escolares, elas têm comparecido no dia a dia dessas/es profissionais.

Através do grupo, conseguimos perceber que essas/es profissionais têm buscado estratégias para atender a queixa escolar, considerando o papel da escola em sua produção. Uma das principais formas de atuação têm sido o acolhimento e a orientação dessas queixas, visando problematizar o olhar dos atores envolvidos. Geralmente, o foco de atendimento ainda tem sido as crianças e suas famílias, pois são elas/es que comparecem ao serviço. Há ainda uma dificuldade em estabelecer um contato sistematizado com a escola, seja por causa da finalidade da política ou por falta de recursos. Foi possível perceber ainda nesses processos de atendimento e entendimento da queixa escolar, que as concepções ainda carregam contradições sobre a produção do fracasso escolar. Em alguns momentos, notamos que o olhar enviesou-se para as famílias, a escola pareceu estar em segundo plano. Isso se aproxima da concepção tradicional sobre a queixa escolar, já discutida anteriormente.

Podemos concluir nesse estudo a importância de refletir sobre a própria prática e o compartilhamento de saberes e experiências entre os profissionais na construção de estratégias para qualificar a atuação frente aos desafios enfrentados. Dentre as estratégias utilizadas, que podem ser potencializadas na desconstrução das queixas escolares que chegam aos serviços, o acolhimento pode ser pensado de forma crítica, levando em consideração os determinantes históricos, políticos, sociais, institucionais e pedagógicos. Dessa forma, nota-se a importância de conceber a queixa escolar e analisá-la desde a formação em Psicologia, visto que, em alguma 
medida, esses elementos farão parte da prática das/os psicólogas/os que atuam com infância e adolescência. Sugere-se como indicativo de pesquisa, compreender na perspectiva daquelas/ es que vivenciam as dificuldades no processo de escolarização, o encaminhamento e atendimento nos serviços de saúde e assistência social.

\section{Referências}

BASTOS, Antônio Virgílio; GONDIM, Sônia Maria Guedes. O trabalho do psicólogo no Brasil. Porto Alegre: Artmed, 2010.

BEATO, Mônica Soares da Fonseca et. al. A psicologia e o trabalho no CRAS. Conselho Regional de Psicologia (CRP-MG), Belo Horizonte, 2011. p. 1-112. Disponível em: < http://docslide.com.br/documents/apsicologia-e-o-trabalho-no-cras-55cac24aea88f.html > . Acesso em: 10 out. 2016.

BRASIL. Ministério do Desenvolvimento Social e Combate à Fome. Política Nacional de Assistência Social (PNAS). Brasília: MDS \SNAS, 2004.

BRASIL. Portaria GM nº 336, de 19 de Fevereiro de 2002. Define e estabelece diretrizes para o funcionamento dos Centros de Atenção Psicossocial. Diário Oficial [da]República Federativa do Brasil, Brasília, DF, 20 fev. 2002.

BRASIL. Política Nacional de Assistência Social. PNAS/2004. 2004. Brasília, DF: MDS. Disponível em:<http://www.slideshare.net/ NormaMuniz/politica-nacional-de-assistencia-social-2013-pnas-2004-enorma-operacional-basica-de-servico-social-2013-nobsuas > . Acesso em: 9 out. 2016

BRASIL. Ministério da Saúde. Secretaria de Atenção à Saúde. DAPE. Coordenação Geral de Saúde Mental. Reforma psiquiátrica e política de saúde mental no Brasil. Documento apresentado à Conferência Regional de Reforma dos Serviços de Saúde Mental: 15 anos depois de Caracas. OPAS. Brasília, novembro de 2005. Disponível em: < http:// bvsms.saude.gov.br/bvs/publicacoes/Relatorio15_anos_Caracas.pdf $>$. Acesso em: 09 out. 2016.

BRASIL. Ministério da Saúde. Portal da Saúde. Política Nacional de Saúde Mental. Brasília, DF, 2011. Disponível em: < http://portal.saude. gov.br/portal/saude/area.cfm?id_area $=925$ > . Acesso em: 01 nov. 2016.

CARVALHO, Denis Barros de; YAMAMOTO, Oswaldo H. Psicologia e políticas públicas de saúde: anotações para uma análise da experiência Brasileira. Psicologia para América. Latina, México , n. 0, ago. 2002. Disponível em < http:// pepsic.bvsalud.org/scielo.php?script $=$ sci_ arttextEpid $=$ S1870-350X2002000100002Elng $=$ ptE $n r m=$ iso $>$. Acesso em: 22 ago. 2017. 
FÓRUM SOBRE MEDICALIZAÇÃO DA EDUCAÇÃO E DA SOCIEDADE. Recomendações de práticas não medicalizantes para profissionais e serviços de educação e saúde. 2. ed. rev. São Paulo, 2013.

FÓRUM SOBRE MEDICALIZAÇÃO DA EDUCAÇÃO E DA SOCIEDADE. Carta do IV Seminário Internacional a Educação Medicalizada: desver o mundo, perturbar os sentidos. Salvador, 2015. Disponível em: <http:// seminario4.medicalizacao.org.br/carta-do-iv-seminario-internacionala-educacaomedicalizada-desver-o-mundo-perturbar-os-sentidos/ > . Acesso em: 2 dez. 2016.

LISBOA, Felipe Stephan; BARBOSA, Altemir José Gonçalves.

Formação em Psicologia no Brasil: um perfil dos cursos de graduação. Psicologia ciência e profissão, Brasília, DF, v. 29, n. 4, p. 718-737, fev. 2009. Disponível em:<http://www.scielo.br/scielo.php?script $=$ sci arttext\&pid $=$ S1414-98932009000400006Elng $=$ en\& $n r m=$ iso $>$. Acesso em: 30 set. 2016.

OLIVEIRA, Katya Luciane et al. The ten-year Scientific production of School and Educational journal (1996/2005). Psicologia escolar e educacional, Campinas, v. 10, n. 2, p. 283-292, dez. 2006.

Disponível em:http://pepsic.bvsalud.org/scielo.php?script = sci_ arttextEpid $=$ S1413-85572006000200011 $E 1 n g=$ ptEnrm = iso. Acesso em: 30 set. 2016.

PATTO, Maria Helena Souza. A família pobre e a escola pública: anotações sobre um desencontro. Psicologia-USP, São Paulo, v. 3, n 1-2, p. 107-121, 1992.

PATTO. A produção do fracasso escolar: histórias de submissão e rebeldia. São Paulo: Casa do Psicólogo, 1999.

PATTO. Psicologia e ideologia: uma introdução crítica à Psicologia Escolar. São Paulo: T. A. Queiroz, 1984.

PEREIRA, Fernanda Martins; PEREIRA NETO, André. O psicólogo no Brasil: notas sobre seu processo de profissionalização. Psicologia em estudo, Maringá, v. 8, n. 2, p. 19-27, dec. 2003. Disponível em: <http://www.scielo.br/scielo.php?script = sci_arttextEpid = S1413$73722003000200003 \& 1 n g=$ en\&nrm $=$ iso $>$. Acesso em: 22 ago. 2017.

SOUZA, Marilene Proença. Psicologia Escolar e Educacional em busca de novas perspectivas. Psicologia Escolar e Educacional, Campinas, v. 13, n. 1, p. 179-182, jan./jun., 2009.

SOUZA, Marilene Proença. Prontuários revelando os bastidores do atendimento psicológico à queixa escolar. Estilos da Clínica, São Paulo, v. X, n. 18, p. 82-107, 2005.

SOUZA, Marilene Proença. A queixa escolar e o predomínio de uma visão de mundo. In: MACHADO, Adriana Marcondes; SOUZA, Marilene Proença Rebello de. Psicologia escolar: em busca de novos rumos. São Paulo: Casa do Psicólogo, 2010, p. 19-37. 
SOUZA, Marilene Proença Rebello de; SILVA, Silvia Maria Cintra da; YAMAMOTO, Katia. Atuação do psicólogo na educação básica: concepções, práticas e desafios. Uberlândia: EDUFU, 2014.

THIOLLENT, Michel. Crítica metodológica, investigação social e enquete operária. São Paulo: Editora Polis, 1980.

VASCONCELOS, Eduardo. Mundos paralelos, até quando?:

Os psicólogos e o campo da saúde mental pública no Brasil nas duas últimas décadas. Mnemosine, Rio de Janeiro, v. 1, n. 0, p.108-134, 2004. Disponível em: <http://www.mnemosine.com.br/ojs/index.php/ mnemosine/article/view/22 > . Acesso em: 09 out. 2016.

VIÉGAS, Lygia de Souza. A atuação do psicólogo na rede pública de educação da Bahia. In: SOUZA, Marilene Proença Rebello; SILVA, Silvia Maria Cintra; YAMAMOTO, Katia. (Org.), Atuação do psicólogo na educação básica: concepções, práticas e desafios. Uberlândia: EDUFU, 2014

YAMAMOTO, Katia. Atuação do psicólogo na educação básica: concepções, práticas e desafios. In: SOUZA, Marilene Proença Rebello; SILVA, Silvia Maria Cintra; YAMAMOTO, Katia. (Org.). Atuação do psicólogo na educação básica: concepções, práticas e desafios. Uberlândia: EDUFU, 2014.

YAMAMOTO, Oswaldo. Políticas sociais, "terceiro setor" e "Compromisso social": perspectivas e limites do trabalho do psicólogo. Psicologia \& Sociedade, Porto Alegre, v.19, n. 1, p. 30-37, 2007.

Submetido em 16/03/2017 | Aceito em 24/09/2017 